\title{
Vibration Response Characteristics of Adjacent Tunnels under Different Blasting Schemes
}

\author{
Jianxin Yu $\mathbb{D},{ }^{1,2}$ Zhibin Zhou, ${ }^{1}$ Xin Zhang, ${ }^{1,3}$ Xiaolin Yang, ${ }^{1}$ Jinxing Wang $\mathbb{D}^{1}$ \\ and Lianhao Zhou ${ }^{1}$ \\ ${ }^{1}$ School of Civil Engineering, Henan Polytechnic University, Jiaozuo, Henan 454003, China \\ ${ }^{2}$ College of Safety Science and Engineering, Henan Polytechnic University, Jiaozuo 454003, China \\ ${ }^{3}$ China Railway 18 Bureau Group Co., Ltd., Tianjin 300222, China
}

Correspondence should be addressed to Jianxin Yu; jianxinyu@hpu.edu.cn and Jinxing Wang; wjx@hpu.edu.cn

Received 13 October 2021; Accepted 8 December 2021; Published 28 December 2021

Academic Editor: Sandro Carbonari

Copyright (c) 2021 Jianxin Yu et al. This is an open access article distributed under the Creative Commons Attribution License, which permits unrestricted use, distribution, and reproduction in any medium, provided the original work is properly cited.

\begin{abstract}
The vibration caused by the tunnel blasting and excavation will harm the surrounding rock and lining structure of the adjacent existing tunnels. This paper takes a two-lane large-span highway tunnel as the research object, conducts on-site monitoring tests on the impact of vibration caused by the blasting and excavation of new tunnels on the existing tunnels under different blasting schemes, and analyses in detail the three-dimension vibration velocity by different excavation footages. From the vibration speed, it is concluded that the influence of the existing tunnel of the newly built tunnel blasting team is affected by various factors, such as distance, free surface, charge, and blasthole distribution. With different blasting schemes, the greater the amount of charge, the greater the vibration caused by blasting. Existing tunnels correspond to the front of the tunnel, and the axial and radial vibration peaks are greater than the vertical. Although the cut segment uses a less amount of explosive and has a less blasthole layout, there is only one free surface. Because of the clamping of the rock, it is compared with the other two segments. The vibration caused is the largest. Although the peripheral holes are filled with a large amount of explosive, the arrangement of the blast holes is relatively scattered and there are many free surfaces. Hence, the vibration caused is the smallest. Corresponding to the back of the tunnel face, since there is no rock clamp, the vibration caused by the cut segment is the smallest, and the vibration caused by the peripheral segment and the floor segment is relatively large. The vibration caused by the front explosion side is significantly greater than the vibration caused by the back explosion side. The vibration velocity caused by the unit charge of $1.5 \mathrm{~m}$ footage is greater than that of the $3.0 \mathrm{~m}$ footage. The vibration velocity caused by the unit charge of the cut segment is the largest, and the vibration velocity caused by the peripheral segment and the floor segment is smaller. The research results provide a reference for the blasting control of similar engineering construction.
\end{abstract}

\section{Introduction}

Tunnel blasting and excavation operations generate vibrations in the surrounding environment. Improperly controlled excavations can readily cause damage to the nearby building structures and, in particular, to the surrounding rock and lining structure of the nearby completed tunnels. Accordingly, the impact of the blasting vibrations on the stability of the adjacent tunnels and surrounding rock has always been a topic of intense research interest worldwide $[1,2]$.
A large number of studies have applied sensors for monitoring the vibrations of the surrounding rock and lining structure of the existing tunnels in response to the blasting conducted at the working face of nearby tunnel excavation. For example, Chen [3] concluded that the peak vibration velocities at each monitoring point lying in front of the working face are less than those at each monitoring point lying behind the face. However, many studies have shown that the peak vibration velocity arising in the vertical direction during tunnel blasting is greater than the peak 
velocities in the other two directions. [4-7] concluded that the vibration velocity in the vertical direction was greater than that in the axial direction by a factor of 3 to 5 . Jia et al. [8] analyzed the influence of blasting vibrations on the lining of an adjacent tunnel under different excavation footage conditions. Sun et al. [9] concluded that the lining of a completed tunnel lying in front of the working face of an adjacent tunnel is directly damaged mainly by the stress waves in the horizontal direction arising from the blasting operation, and the radial vibration velocity is greater than the velocities of the other two directions. Xia et al. [10] applied numerical simulations and engineering practices to conclude that the lining structure and surrounding rock of an existing tunnel would not be damaged when the peak particle velocity (PPV) was less than $0.30 \mathrm{~m} / \mathrm{s}$. In addition, numerous studies have demonstrated that the explosive charge is a key parameter for controlling the level of vibrations generated during tunnel blasting [11-14]. Other studies demonstrated that the vault of the vertical intersection point of the maximum principal stress and the maximum vibration velocity arising in an existing tunnel lining under blasting at the working face of an adjacent tunnel would lead to the secondary settlement of the existing tunnel vault $[15,16]$. Zhou [17] determined that the vibration generated by the center diaphragm (CD) blasting was only $28 \%$ of the full blasting at the same distance. The peak tensile stress caused by comprehensive blasting may lead to lining failure. Dang et al. [18] combined numerical simulation and on-site monitoring data to investigate the effects of blasting vibration on the safety of buildings, existing tunnels, buried pipelines, and roadways from the aspects of seismic velocity, blasting seismic waves, and blasting load.

Other studies have demonstrated that the vibration is related to the distance of the blasting source, and the vibration velocity of the existing tunnel caused by blasting in the adjacent tunnel decreases significantly with the increase of blasting distance [19-21]. In addition, blasting operations in an adjacent tunnel generate peak vibration velocities on the side of an existing tunnel nearest to the adjacent tunnel under excavation, and these vibration velocities are significantly greater than those monitored on the side of the existing tunnel farthest from the adjacent tunnel $[22,23]$. Other studies have considered the effects of different types of blasting operations. For example, Zhou et al. [24] concluded that the upper bench blasting generates vibrations that are greater in the radial direction than in the other two directions in an adjacent existing tunnel, while the lower bench blasting induces a maximum vibration velocity in the vertical direction. Yu et al. [25] conducted the on-site vibration monitoring in a tunnel being excavated by cutting blasting operations and determined that the vibrations on the unexcavated rock mass ahead of the working face were greater than that in the excavated rock wall behind. Meanwhile, the influence of the auxiliary and bottom blastings in the regions ahead and behind the blasting face was found to be the same. Xue et al. [26] proposed that the maximum peak particle velocity (PPV) is located on the haunch of the lining facing the blasting source and that the PPV and peak tensile stress decrease with the increase in the surrounding rock grade. $\mathrm{Wu}$ et al. [27] proposed that the working face formed in the blasting excavation area of the new tunnel will increase the vibration velocity of the adjacent built tunnel. The results of the analysis performed by Rebello et al. [28] reveal that the response of the buildings in the softer strata and lower frequencies leads to the greater magnification of velocities and displacements compared to the response of the buildings in the stiff strata. Wu et al. [29] obtained the maximum single-shot charge during blasting construction by combining the vibration attenuation law generated by blasting. Hu et al. [30] used the current regression method of Sadov's formula to establish the blasting vibration model based on the actual project, which provided the basis for the maximum charge of a single segment in blasting construction. Guo et al. [31] identified through experiments that the blast side of the existing tunnel was a triangular failure, and the arch point and the foot of the back blast side were cracked. Over time, the failure weakened. Qian et al. [32] through practical engineering and numerical simulation concluded that the use of skylight points can effectively reduce the vibration of existing tunnels, speed up the construction progress, and improve economic benefits. Wang et al. [33] concluded that the vibration velocity peak value along the radial direction of each measuring point near the blasting side of the existing tunnel is the largest, and the direction of the vibration velocity peak value at the back blasting side is changed. The peak vibration velocity of the back blasting side is much smaller than that of the front blasting side, and the peak vibration velocity of the arch rib of the front blasting side is the highest.

The above-discussed studies have greatly contributed to our understanding of the vibrations induced in an existing tunnel because of the blasting operations conducted in a nearby tunnel. However, we note that these studies usually only consider the change of the individual blasting parameters and rarely study the combined effects of the investigation parameters. The present work addresses this issue by considering a double-track long-span highway tunnel and conducting field monitoring testing of the vibration velocities arising in the completed tunnel because of blasting in the closely adjacent tunnel under different blasting schemes. These schemes consider different footage conditions, blast hole categories, numbers of holes, hole depths, and single-hole and singlesegment explosive charges. The tests mainly consider the blasting segments representative of cutting blasting, floor blasting, and contour blasting. These results provide a reference for conducting blasting vibration control in similar engineering constructions.

\section{Engineering Background}

The newly built Zoumagang Highway Tunnel is a one-way two-hole separated tunnel with a clear distance between the left and right lines of $28.5 \mathrm{~m}$, an excavation section of the left line of $16.5 \mathrm{~m} \times 9.5 \mathrm{~m}$, and an excavation section of the right line of $16.78 \mathrm{~m} \times 10.11 \mathrm{~m}$. The tunnel surrounding rock in the test section is of grade III, composed of medium-toslightly weathered mixed granite. The rock is hard, high in strength, slightly weathered, with slightly developed cracks. The underground water in the tunnel shows local seepage or dripping. The construction site adopts the method of up and 
down long steps for excavation. The excavation height of the upper step is $7.35 \mathrm{~m}$, the height of the lower step is $3.66 \mathrm{~m}$, and the distance between the upper and lower steps is greater than $50 \mathrm{~m}$.

Two different blasting footage plans were used for the construction on-site, namely $3.0 \mathrm{~m}$ footage and $1.5 \mathrm{~m}$ footage. The following $3.0 \mathrm{~m}$ footage takes the 5 -segment cut holes as an example, and the $1.5 \mathrm{~m}$ footage uses the 1segment cut holes as an example. The bottom plate holes and peripheral holes have 15 and 19 segments as an example. The layout of the blast holes under different footage conditions is shown in Figure 1, and the blasting parameters are shown in Table 1. The blasting plan for the upper step excavation is a wedge-shaped cut, a segmented delay, and a smooth-surfaced blasting method. Explosive materials are 2\# rock emulsion explosive and detonating cord detonators. The charge structure of each segment is axially continuous and radially uncoupled. Except for the surrounding segment that is blocked by a carton absorption material, the other blast holes are not blocked.

\section{Experimental Scheme}

The overall testing scheme is illustrated in Figure 2. The Chinese GB6722-2014 standard (blasting safety regulations) applies the vibration velocity as the main control index during the blasting operations. Therefore, the vibrations were monitored using TC-4850 blasting vibration measurement sensors (Chengdu Science and Technology Co.), which are three-dimensional (3D)-integrated velocity sensors operating in the $X, Y$, and $Z$ directions. The monitoring points were arranged along the tunnel axis ahead of (scheme 1) and behind (scheme 2) the corresponding blasting face of the tunnel under excavation, and the vibration sensors were fixed on the sidewall of the completed tunnel at each monitoring point corresponding to the position identified as $\mathrm{A}$ in scheme 3 of Figure 1 (because of the change of blasting footage, the measuring point arrangement distance also has a little change but is controlled in the range of $3-5 \mathrm{~m}$ ). The sensors were glued to the surface of the lining structure using a paste composed of gypsum powder and water. In addition, the expansion screw holes were punched into the lining structure, and the sensors were firmly anchored by stainless steel clips affixed by the expansion screws to ensure that the sensors vibrated simultaneously with the lining structure. The $X$ direction of the sensors corresponded to the horizontal direction parallel to the axis of the tunnel. The $Y$ direction corresponded to the axial direction perpendicular to the vertical walls of the tunnel, and the $Z$ direction corresponded to the vertical direction. These sensors were applied for monitoring the $3 \mathrm{D}$ vibration velocities in the lining structure of the completed tunnel, according to previous research [34].

\section{Vibration Propagation ahead of the Blasting Face}

Combined with the blasting excavation scheme, the field data are analyzed. Under the condition of the full-section blasting of the rear tunnel, the vibration of the lining structure of the front tunnel caused by the typical blasting segment and the propagation attenuation characteristics of the $X, Y$, and $Z$ components are obtained. The attenuation trend of the three-dimensional peak vibration velocity caused by the blasting is analyzed, as shown in Figure 3. Here, the distance in front of blasting is positive.

At the same time, the combined velocity of each typical segment of the two footages $S=\sqrt{ }(X 2+Y 2+Z 2)$ is taken as the object for comparative analysis, and the velocity attenuation diagram is drawn, as shown in Figure 4. In addition, because of the difference in the explosive loading of the two footages, the explosive loading of each typical segment is also different. To accurately analyze the damage degree of each segment blasting corresponding to each footage, the combined velocity is divided by the corresponding dosage, and the variation law of vibration velocity caused by unit dosage with distance is obtained, as shown in Figure 5.

Figure 3 shows that the front of the tunnel face is affected by blasting excavation near the tunnel. The $3.0 \mathrm{~m}$ feed loading of each segment is greater than $1.5 \mathrm{~m}$ feed loading, and hence, the vibration peak caused by $3.0 \mathrm{~m}$ feed is larger than that caused by $1.5 \mathrm{~m}$ feed. The vibration peak of $3.0 \mathrm{~m}$ footage in the three directions is about twice that of the $1.5 \mathrm{~m}$ footage. When the vibration of each typical segment propagates at the distance of the first $13 \mathrm{~m}$, the vibration velocities in the $X$ and $Y$ directions gradually decrease with the increase of distance and are greater than those in the $Z$ direction. However, when the distance exceeds $20 \mathrm{~m}$, the vibration velocity in the $Z$ direction gradually occupies the dominant position, showing an enhanced trend. It shows that the vibration of the existing tunnel lining structure caused by new tunnel blasting is mainly reflected in the axial and radial direction, and the vertical influence range is wide. Therefore, it is necessary to focus on monitoring the vibration effect of blasting on the existing tunnel in the $X$ and $Y$ directions and expand the vibration monitoring range in the $Z$ direction.

As the tunnel adopts the method of stage-delayed blasting, it is affected by many factors, such as distance, free surface, dosage, and distribution of blasting holes. There is only one free surface when the cut segment is blasting, and the vibration is produced by the rock clip when it propagates in front of the tunnel. Even if the amount of charge and hole in the cut segment is the least, the vibration caused by blasting is greater than that of other segments. The charge in the surrounding segment is the largest, and the number of blastholes is the largest, however, the blasthole layout is relatively dispersed around the tunnel, with the largest free surface and the smallest vibration velocity caused by blasting. At the same time, with the increase of the distance from the blasting center to the measuring point, the vibration caused by the different footage blasting schemes in each segment shows a decreasing trend (Figure 4). It can be seen that the maximum vibration in front of the tunnel face caused by the tunnel blasting construction is not necessarily the maximum charge segment. Therefore, in the study of tunnel blasting vibration, a detailed analysis should be carried out according to different blasting segments of different schemes. 


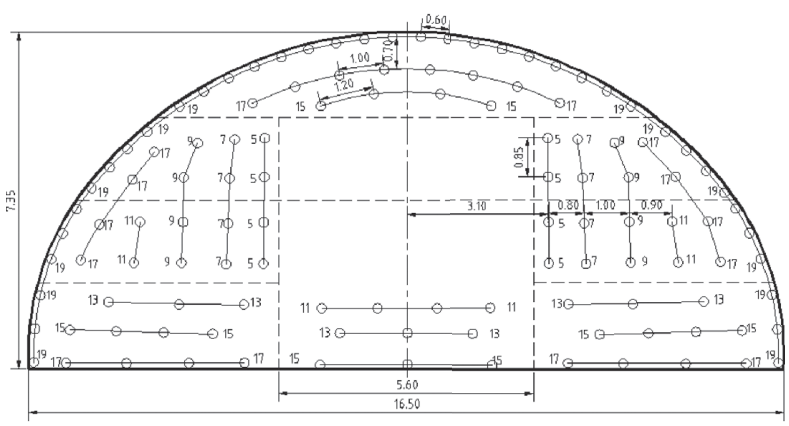

(a)

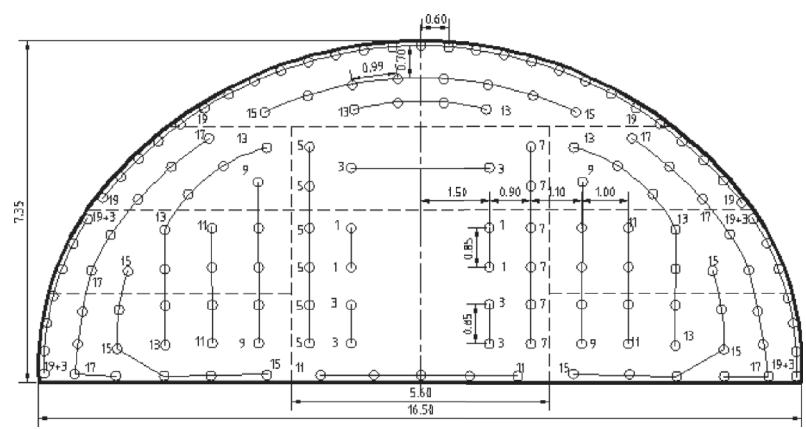

(b)

Figure 1: Arrangement of blastholes: (a) $3.0 \mathrm{~m}$ blasting scheme and (b) $1.5 \mathrm{~m}$ blasting scheme.

Figure 5: a comparative analysis of vibration velocity caused by the unit charge of different footage in each blasting segment shows that the vibration velocity caused by the unit charge of $3.0 \mathrm{~m}$ footage in each typical blasting segment is the smallest, and the vibration velocity caused by the unit charge of $1.5 \mathrm{~m}$ footage is relatively large. In the two different blasting schemes, the vibration velocity caused by the unit charge in the cutting segment is the largest, the vibration velocity caused by the unit charge in the surrounding segment is the smallest, and the vibration caused by the unit charge in the floor segment is in the middle. Taking the cutting segment as an example, the dosage of the cutting segment with the $3.0 \mathrm{~m}$ footage is 6 to 8 times higher than that with $1.5 \mathrm{~m}$ footage, and the peak vibration velocity caused by the $3.0 \mathrm{~m}$ footage is 2 to 4 times higher than that of the other two schemes. Therefore, the vibration velocity caused by the unit dose of $3.0 \mathrm{~m}$ footage is less than that caused by the unit dose of $1.5 \mathrm{~m}$ footage, and other sections are also affected. In the actual construction blasting, we should strictly control the vibration velocity of the cutting segment and make effective protective measures. According to the above analysis, we can conclude that in the tunnel blasting construction, the blasting distance, free surface, and the distribution of blasting holes will have a vibration impact on the existing buildings in front of the blasting face.

\section{Vibration Propagation behind the Blasting Face}

The 3D peak vibration velocity attenuation trends obtained at the monitoring points positioned behind the corresponding blasting face for the typical blasting segments under the two footage conditions are presented in Figure 6. Here, the distances behind the blasting face are given as negative values. In addition, the attenuation trends in the peak vibration velocity $S$ obtained at the monitoring points positioned behind the corresponding blasting face for the two footage conditions are presented in Figure 7. Finally, the ratio of $\mathrm{S}$ to the single-segment explosive charge at the monitoring points positioned behind the corresponding blasting face for the two footage conditions are presented in Figure 8.

The $3 \mathrm{D}$ vibration velocity attenuation trends observed in Figure 6 are very similar to the trends observed in Figure 3 for the monitoring points ahead of the blasting face. Again, we note that the vibration velocities induced by each blasting segment under the $3.0 \mathrm{~m}$ footage condition are greater than those observed under the $1.5 \mathrm{~m}$ footage conditions. Furthermore, the $3 \mathrm{D}$ vibration velocities caused by the cutting blasting segment are the smallest behind the corresponding working face. It is because there is no rock clamp behind the blasting face, and there is a large free surface that plays a role in vibration isolation to reduce the vibration caused by the blasting. On the contrary, the vibration caused by the distribution of the bottom plate and the surrounding segment is relatively large because of the distribution of the blast hole near the first tunnel and the large dosage. The vibration velocities generated under the different footage conditions in the $X$ and $Y$ directions of each blasting segment are greater than those in the $Z$ direction. The generally greater vibration velocity observed for the floor and contour blasting segments than those observed for the cutting blasting segment is more clearly indicated in Figure 7. The vibration velocity trends caused by a unit explosive charge under each footage condition shown in Figure 8 are also similar to those observed in Figure 5. The vibration velocity caused by the unit charge amount of $3.0 \mathrm{~m}$ footage in each segment is less than $1.5 \mathrm{~m}$ footage, where the vibration velocity caused by a unit explosive charge under each footage condition is the largest in the cutting blasting segments. The vibration velocity generated by a unit explosive charge is the smallest for the contour segments.

\section{Distribution of Blasting Vibration Velocities along the Completed Tunnel}

6.1. Tunnel Arch. According to the scheme in Figure 2 the $3 \mathrm{D}$ peak vibration velocities obtained at the monitoring points $\mathrm{A}, \mathrm{B}, \mathrm{C}$, and $\mathrm{D}$ positioned on the arch of the completed tunnel at a position commensurate with the corresponding blasting face are presented in Figure 9 for typical blasting segments under the footage conditions of $3.0 \mathrm{~m}$ and $1.5 \mathrm{~m}$. In addition, attenuation trends in the peak vibration velocity $S$ obtained at the monitoring points $A, B, C$, and $D$ are presented in Figure 10, and the ratio of $S$ to the singlesegment explosive charge at the monitoring points $\mathrm{A}, \mathrm{B}, \mathrm{C}$, and $\mathrm{D}$ are presented in Figure 11.

The vibration velocities observed under each typical blasting segment in Figure 9 exhibit obvious trends. 
TABLE 1: Blasting parameters.

\begin{tabular}{|c|c|c|c|c|c|c|c|c|c|}
\hline \multicolumn{5}{|c|}{$3.0 \mathrm{~m}$ blasting scheme } & \multicolumn{5}{|c|}{$1.5 \mathrm{~m}$ blasting scheme } \\
\hline $\begin{array}{l}\text { Number of } \\
\text { stages }\end{array}$ & $\begin{array}{c}\text { Hole } \\
\text { depth (m) }\end{array}$ & $\begin{array}{c}\text { Number of } \\
\text { holes }\end{array}$ & $\begin{array}{l}\text { Single-hole } \\
\text { dose (kg) }\end{array}$ & $\begin{array}{c}\text { Total } \\
\text { charge }(\mathrm{kg})\end{array}$ & $\begin{array}{c}\text { Number of } \\
\text { stages }\end{array}$ & $\begin{array}{c}\text { Hole } \\
\text { depth (m) }\end{array}$ & $\begin{array}{c}\text { Number of } \\
\text { holes }\end{array}$ & $\begin{array}{l}\text { Single-hole } \\
\text { dose }(\mathrm{kg})\end{array}$ & $\begin{array}{c}\text { Total } \\
\text { charge }(\mathrm{kg})\end{array}$ \\
\hline 5 & 4.5 & 8 & 3.0 & 24 & 1 & 3 & 4 & 1.2 & 4.8 \\
\hline \multirow{3}{*}{15} & 4 & 4 & 1.5 & \multirow{3}{*}{32.4} & \multirow{3}{*}{15} & 2 & 6 & 0.8 & \multirow{3}{*}{12.8} \\
\hline & 4 & 8 & 2.4 & & & 1.8 & 8 & 1 & \\
\hline & 4 & 3 & 2.4 & & & 2 & 8 & 0.6 & \\
\hline \multirow{3}{*}{19} & 3.5 & 14 & 1.5 & \multirow{3}{*}{54} & \multirow{3}{*}{19} & 1.7 & 27 & 0.5 & \multirow{3}{*}{22.7} \\
\hline & 3.5 & 4 & 1.8 & & & 1.8 & 12 & 0.6 & \\
\hline & 2.8 & 2 & 2.4 & & & 1.8 & 2 & 1 & \\
\hline
\end{tabular}

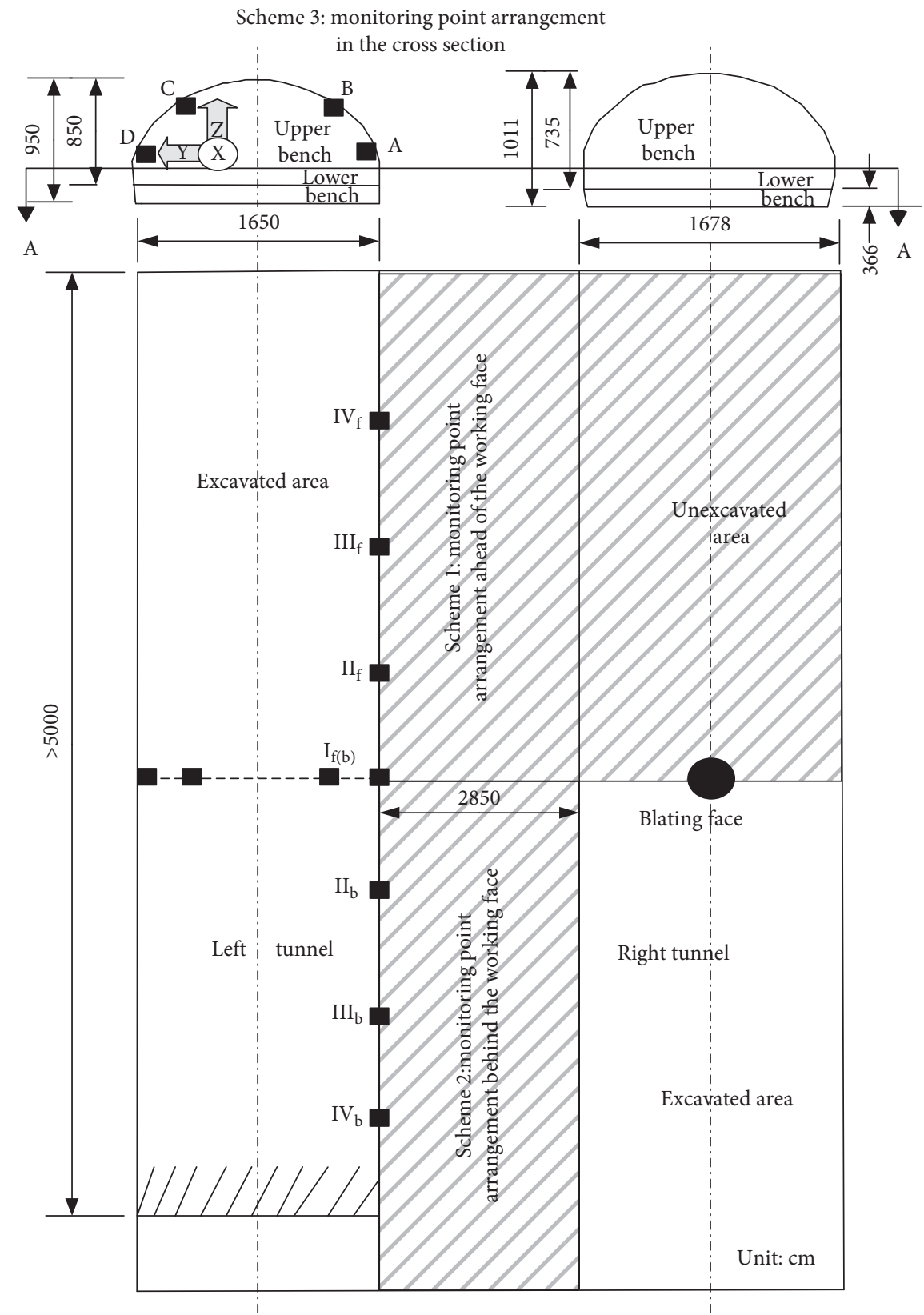

FIGURE 2: Relationship between the two tunnels and the layout scheme of monitoring points (unit: $\mathrm{cm}$ ). 


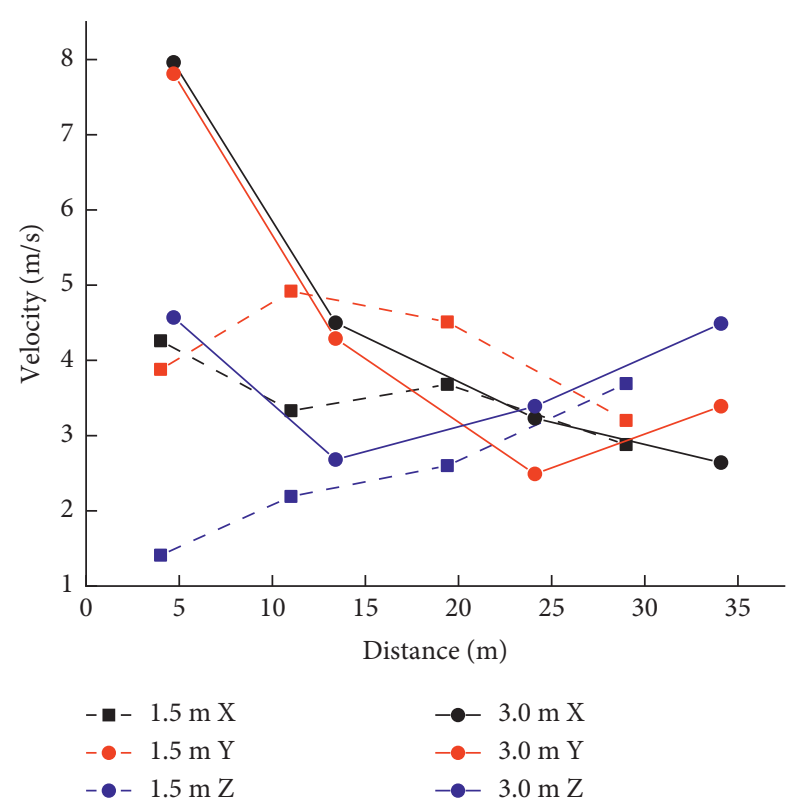

(a)

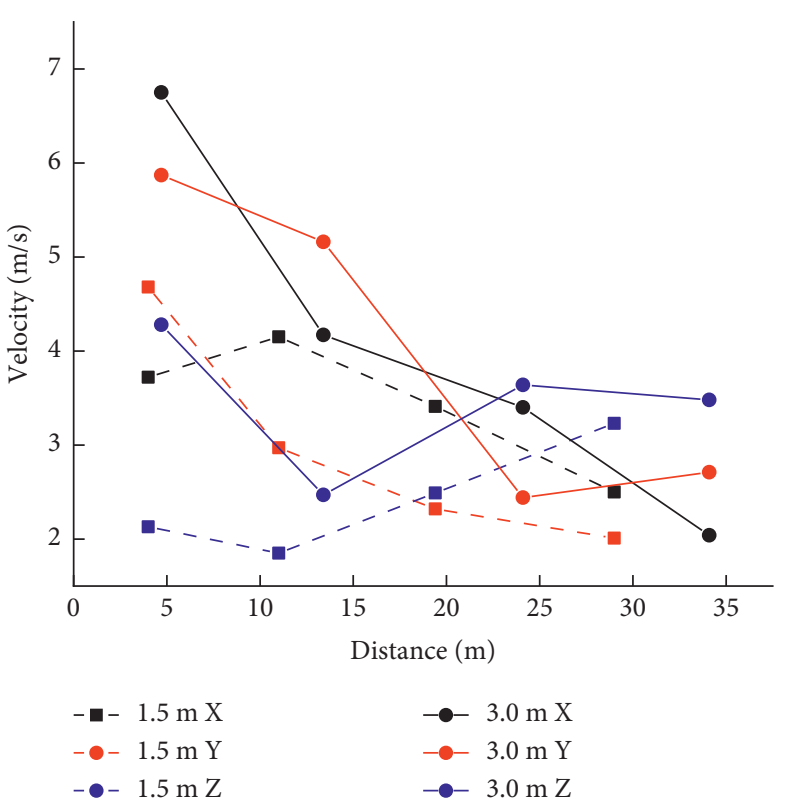

(b)

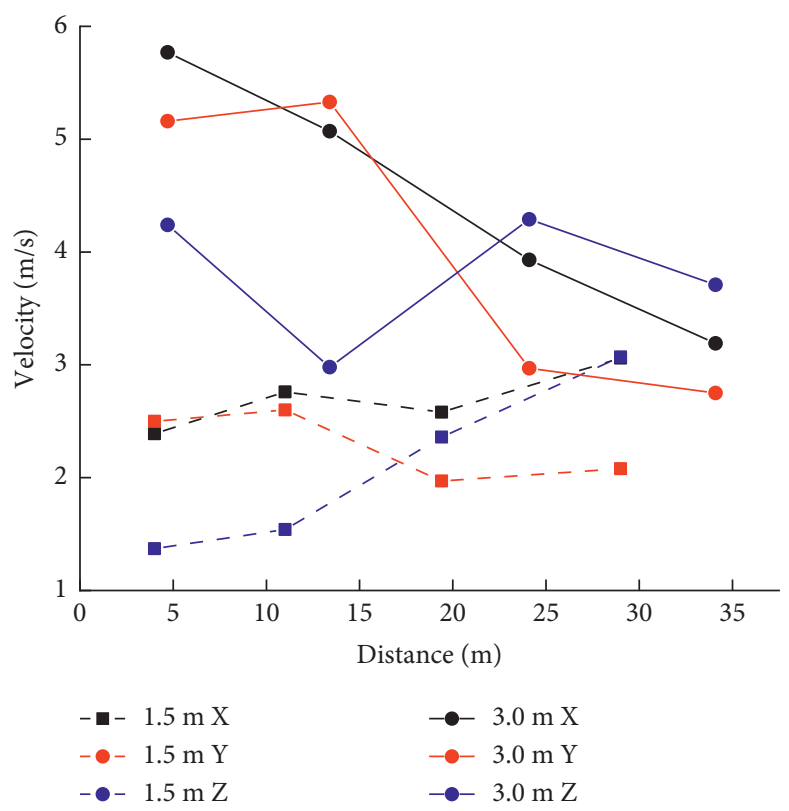

(c)

FIGURE 3: Comparison of 3D vibration velocities of typical blasting segments with different footage conditions ahead of the corresponding blasting face. (a) Cutting segment, (b) floor segment, and (c) contour segment.

Firstly, it can be concluded that the vibration velocities generated under the $3.0 \mathrm{~m}$ footage condition are greater than those generated under the $1.5 \mathrm{~m}$ footage condition under all blasting conditions considered, and the vibration velocities observed at the monitoring point $\mathrm{A}$ near the sidewall facing the blasting face are generally much greater. We also note from Figure 10 that the vibration velocity observed at the monitoring points $\mathrm{A}$ and $\mathrm{B}$ are generally much greater for the floor blasting segment than those observed for the cutting and contour blasting segments. Finally, the results in Figure 11 indicate that the vibration velocity obtained per unit explosive charge at the monitoring points $\mathrm{A}$ and $\mathrm{B}$ are very much greater than those observed at the monitoring points $\mathrm{C}$ and $\mathrm{D}$, and the vibration velocity per unit explosive charge at the monitoring points $\mathrm{A}$ and $\mathrm{B}$ because of the cutting blasting segment are the largest, while those because of the contour blasting segment are the smallest. 


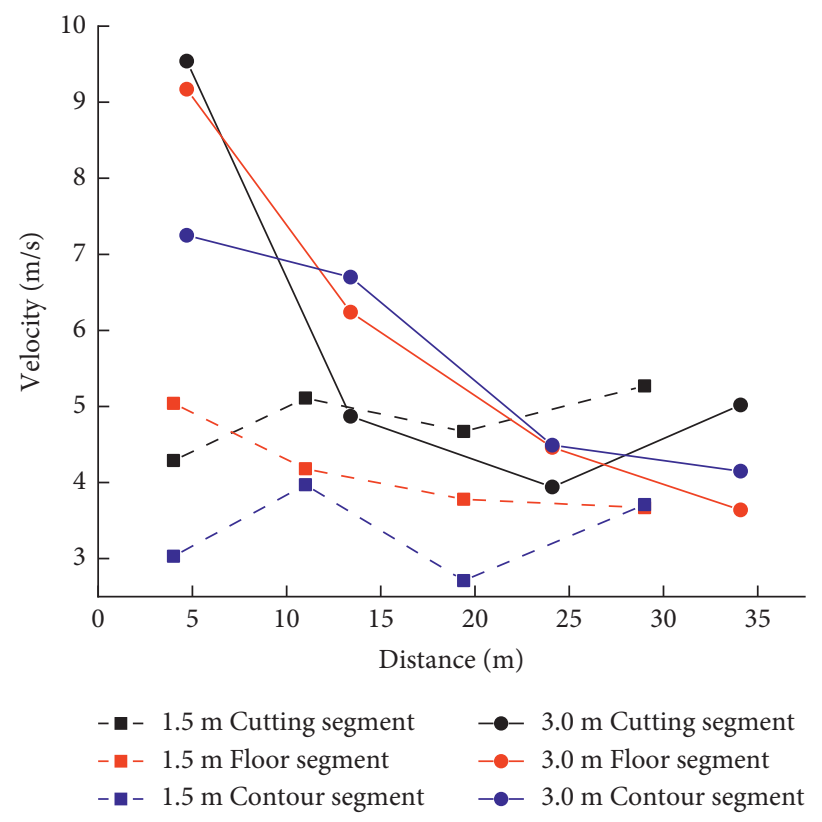

FIgURE 4: Comparison of the vibration velocity of typical blasting segments with different footage conditions ahead of the corresponding blasting face.

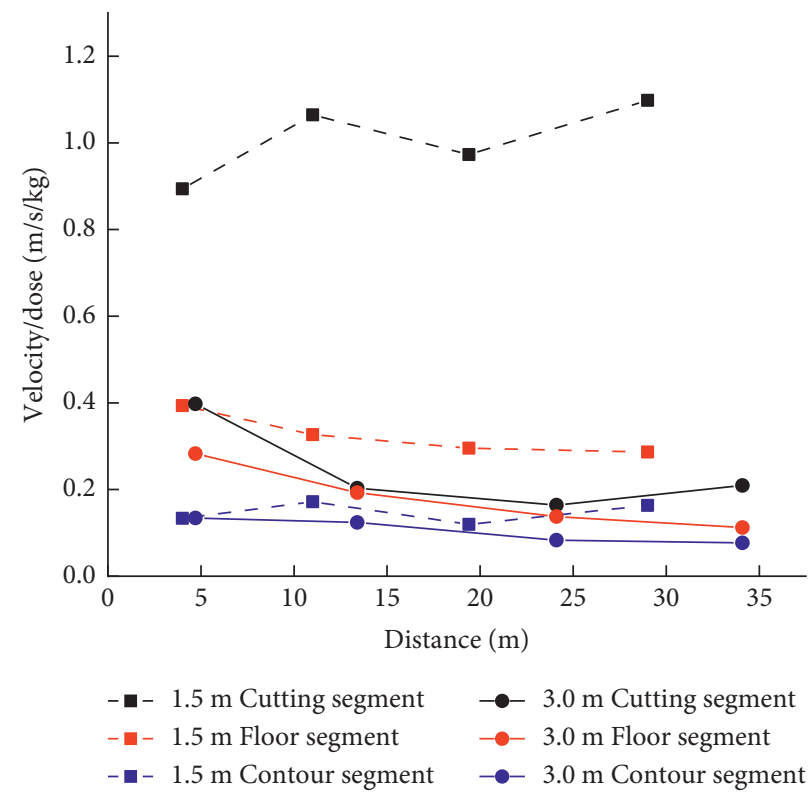

FIGURE 5: Comparison of the ratios of the vibration velocity to single-segment explosive charge of typical blasting segments with different footage conditions ahead of the corresponding blasting face. 


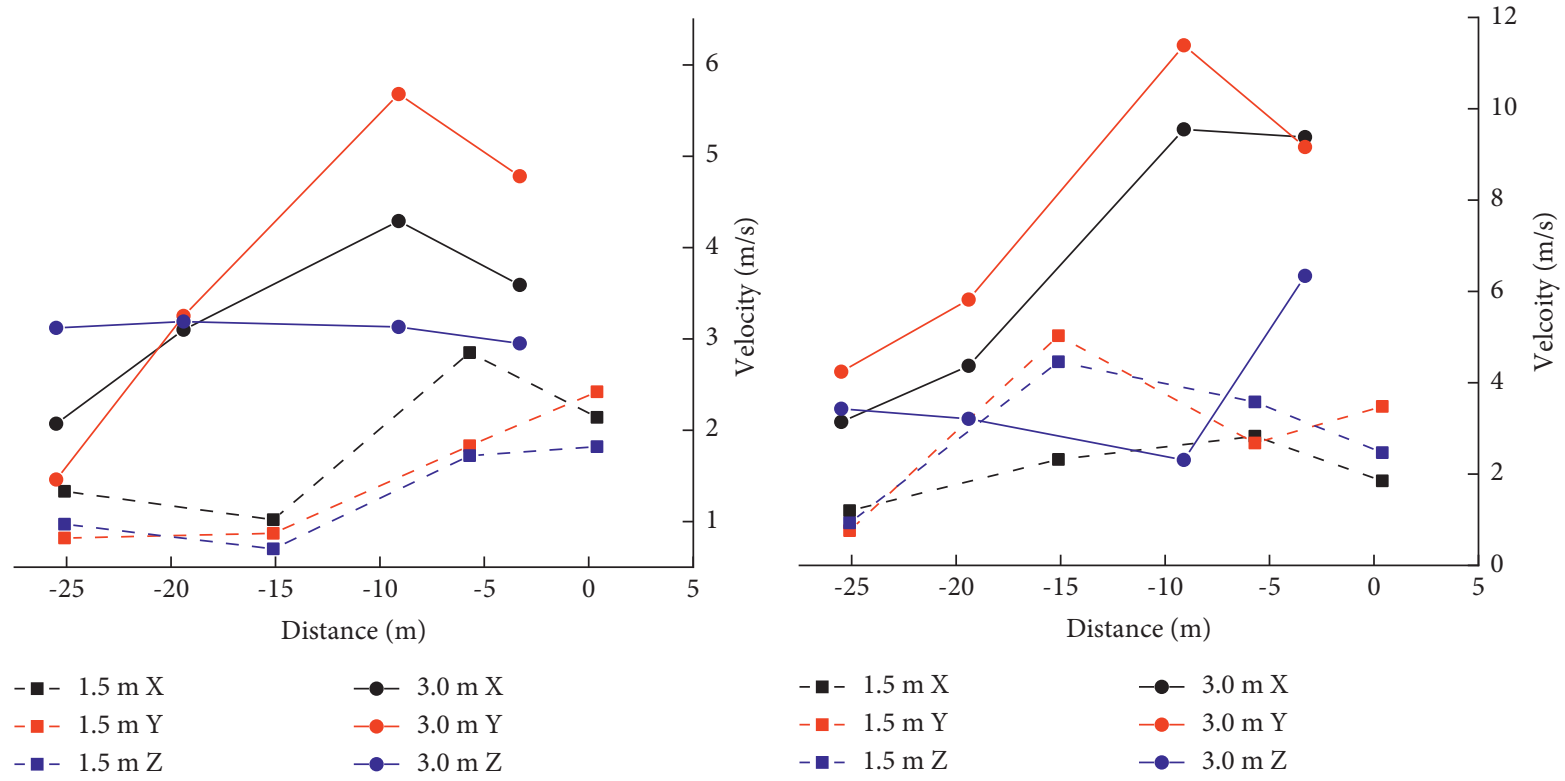

(a)

(b)

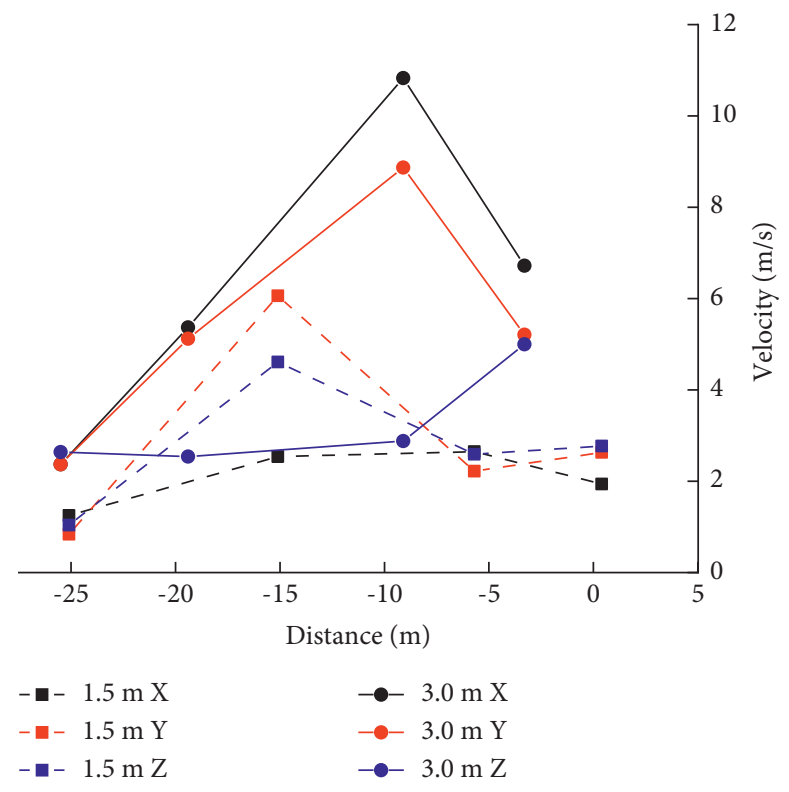

(c)

Figure 6: Comparison of 3D vibration velocities of typical blasting segments with different footage conditions behind the corresponding blasting face. (a) Cutting segment, (b) floor segment, and (c) contour segment. 


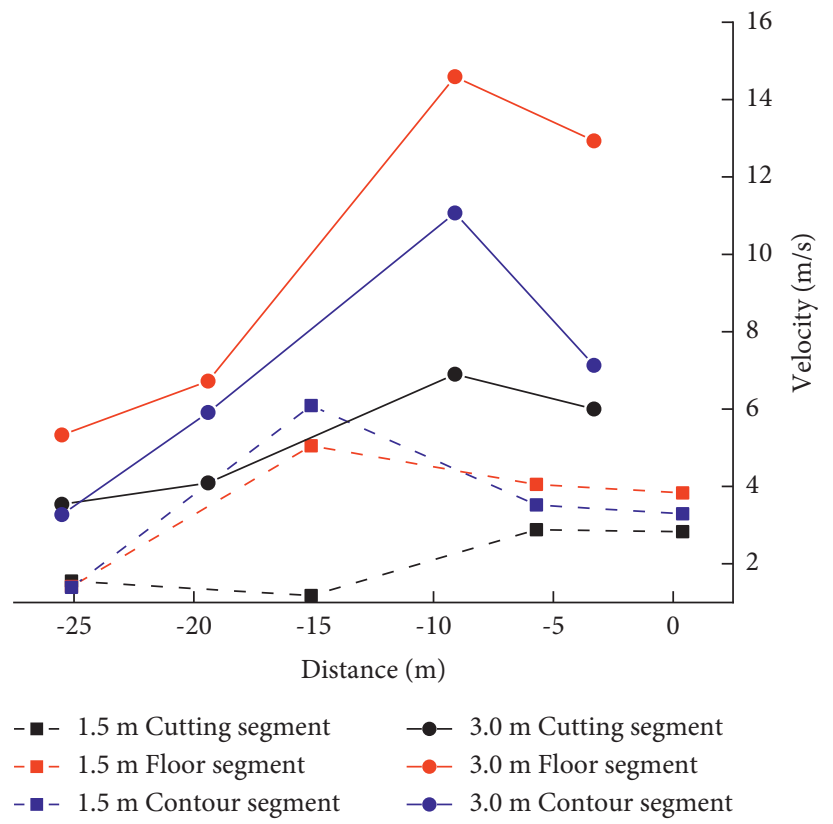

FIGURE 7: Comparison of the vibration velocity of the typical blasting segments with different footage conditions behind the corresponding blasting face.

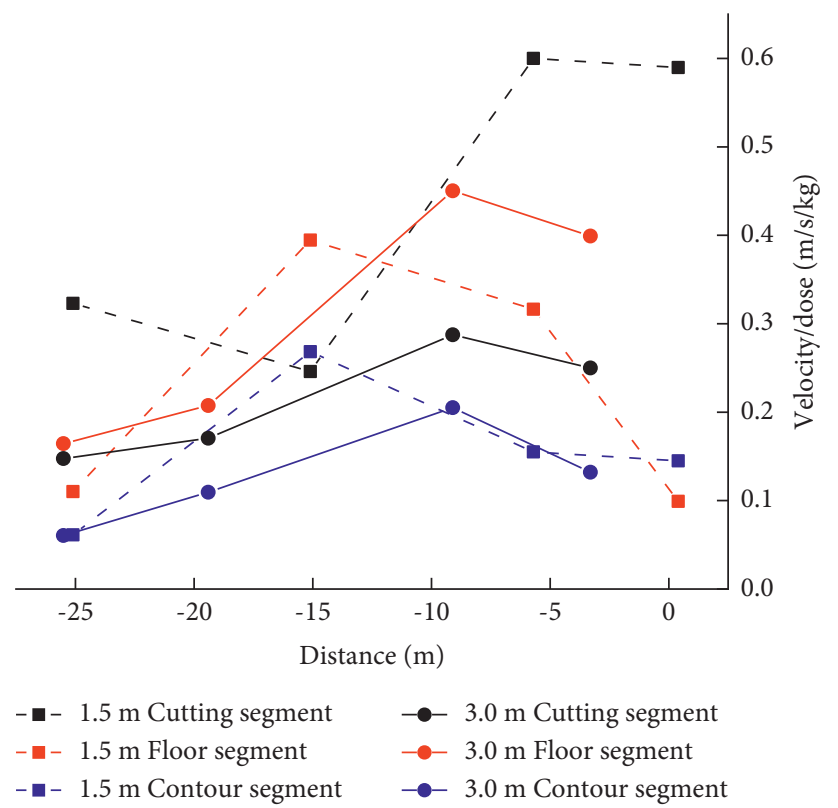

FIGURE 8: Comparison of the ratios of the vibration velocity to single-segment explosive charge of the typical blasting segments with different footage conditions behind the corresponding blasting face. 

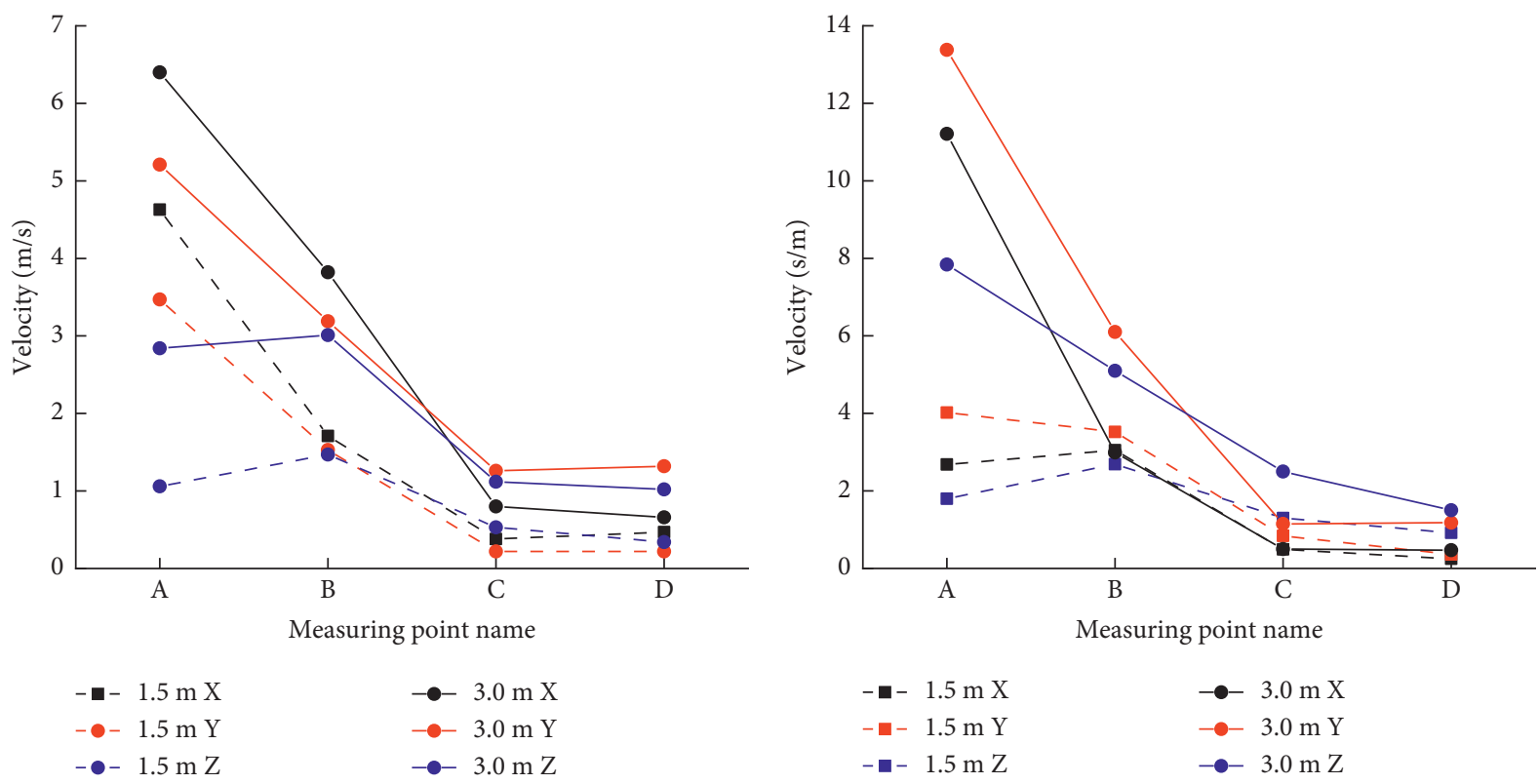

(a)

(b)

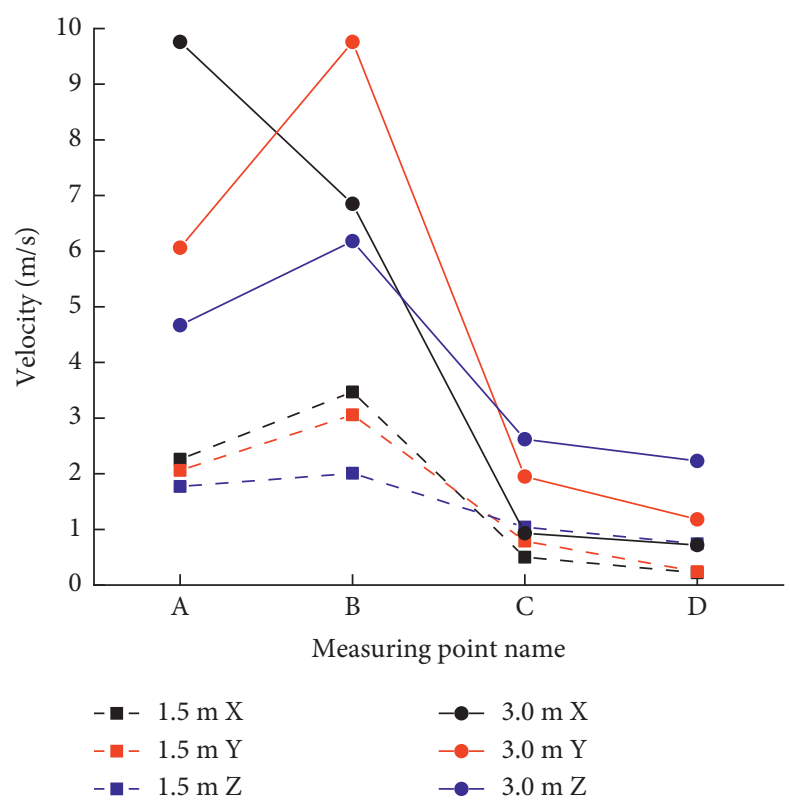

(c)

FIGURE 9: Comparison of 3D vibration velocities of typical blasting segments with different footage conditions at the monitoring points A, B, $\mathrm{C}$, and $\mathrm{D}$ positioned on the arch of the completed tunnel at a position commensurate with the corresponding blasting face. (a) Cutting segment, (b) floor segment, and (c) contour segment. 


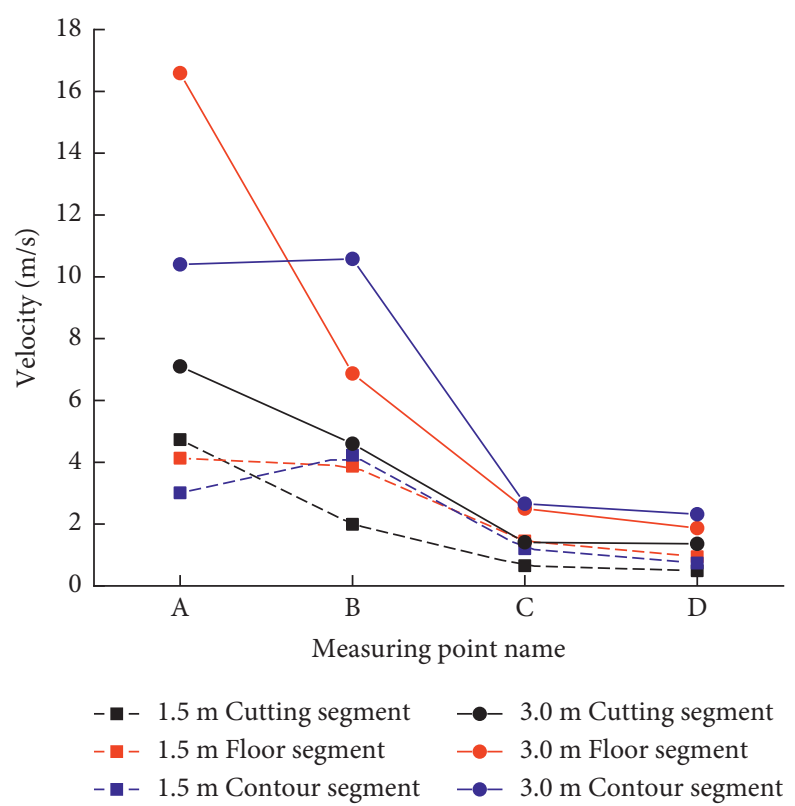

FIGURE 10: Comparison of the vibration velocity of typical blasting segments with different footage conditions at the monitoring points A, B, $\mathrm{C}$, and $\mathrm{D}$.

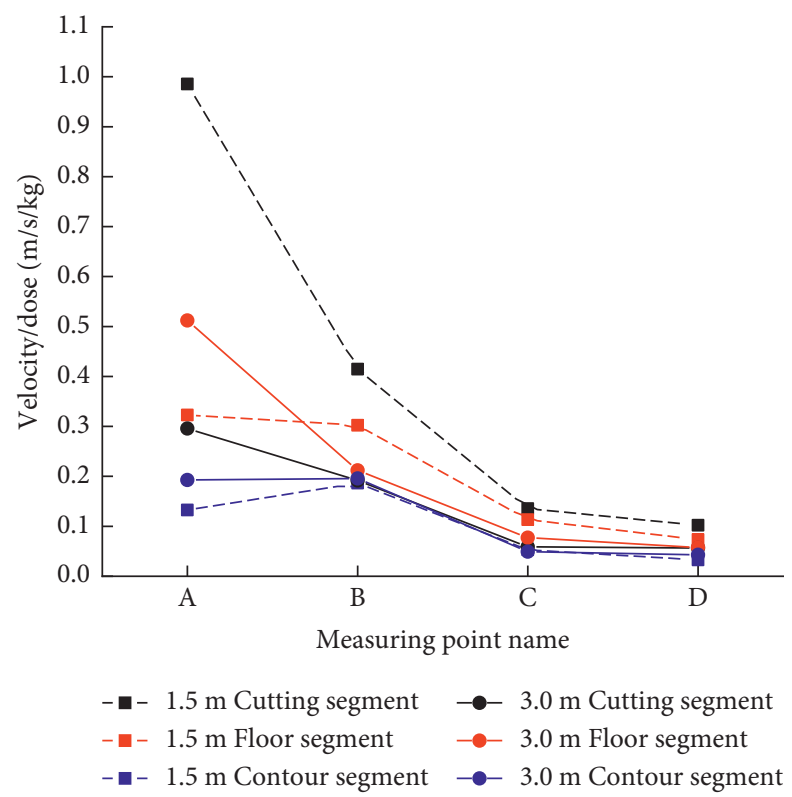

FIGURE 11: Comparison of the ratios of the vibration velocity to a single-segment explosive charge of the typical blasting segments with different footage conditions at the monitoring points $\mathrm{A}, \mathrm{B}, \mathrm{C}$, and $\mathrm{D}$.

\section{Conclusion}

This study involves in situ monitoring and testing the vibration velocity generated in the completed tunnel due to the blasting of adjacent tunnels under a wide range of blasting schemes. To this end, the $3 \mathrm{D}$ vibration velocity generated at the monitoring point under three monitoring schemes under different excavation footage conditions is analyzed in detail. The main conclusions of the study are given as follows:
(1) Corresponding to the front of the blasting face, the dosage of $3.0 \mathrm{~m}$ footage in each typical segment is larger than that of $1.5 \mathrm{~m}$, and hence, the vibration is also the largest. The vibration peak value of the axial and radial is greater than that of the vertical. The vibration of the adjacent tunnel caused by the cutting segment is the largest, and the surrounding segment and the floor segment are smaller. With the increase of the distance between the measuring point and the blasting center, the vibration caused by blasting 
shows a decreasing trend. Under two different footage conditions, the vibration velocity caused by the unit charge of the cutting segment is the largest, and the vibration caused by the surrounding segment is the smallest. The vibration caused by the unit charge of $3.0 \mathrm{~m}$ footage in each typical segment is smaller than that caused by the unit charge of $1.5 \mathrm{~m}$ footage.

(2) The 3D vibration velocities in the completed tunnel behind the corresponding blasting face were greater under the $3.0 \mathrm{~m}$ footage condition than those obtained under the $1.5 \mathrm{~m}$ footage conditions for all blasting segments considered. The cutting blasting segments generated the smallest vibration velocities, and the contour blasting segments generated the largest vibration velocities under all two footage conditions. However, the vibration velocities generated by a unit explosive charge were still the greatest for the cutting blasting segments, whereas those generated by the contour blasting segments were the smallest under all three footage conditions.

(3) The results obtained for scheme 3 exhibited obvious trends, with the vibration velocities observed at the monitoring points facing the blasting face being significantly greater than those on the backside for both footage conditions and all blasting segments considered. The vibration velocities generated by a unit explosive charge were the greatest for the cutting blasting segments, and those obtained for the contour blasting segments were the smallest.

(4) In the actual construction blasting, we should strictly control the vibration velocity of the cutting segment and make effective protective measures. According to the above analysis, we can conclude that in the tunnel blasting construction, blasting distance, free surface, and the distribution of blasting holes will have an impact on the adjacent existing tunnel.

\section{Data Availability}

The data used to support the findings of this study are included within the article.

\section{Conflicts of Interest}

The authors declare that there are no conflicts of interest regarding the publication of this paper.

\section{Acknowledgments}

This work was supported by the National Natural Science Foundation of China (No. 42107200), Innovation and Entrepreneurship Project of China Occupational Safety and Health Association (No. CXCY-2021-23), and Key Science and Technology Program of Henan Province (No. 212102310598). The authors would like to thank the researchers of past studies in the field for their excellent work and their help in providing references for this paper.

\section{References}

[1] M. N. Wang, X. M. Pan, C. M. Zhang, X. D. Wen, and K. K. Wang, "Study of blasting vibration influence on closespaced tunnel," Rock and Soil Mechanics, vol. 25, no. 3, pp. 412-414, 2004.

[2] Y. S. Shen, B. Gao, Z. J. Wang, and Z. J. Meng, "Effect of blasting in double line tunnel on existing tunnel," Chinese Journal of Underground Space and Engineering, vol. 05, pp. 980-984, 2009.

[3] L. J. Chen, "Experimental study on blasting vibration influence on nearby tunnels with small interval," Blasting, vol. 27, no. 2, pp. 36-40, 2000.

[4] D. W. Zhong, L. Wu, and G. Yu, "Study on effect of tunnelling blasting on existing adjacent tunnel," Materials Research Innovations, vol. 15, no. s1, pp. 513-516, 2011.

[5] D. H. Hu and J. C. Duan, "Analysis of vibration characteristics of new subway tunnel undercrossing the existing highway under blasting construction," DEStech Transactions on Materials Science and Engineering, vol. 21, 2016.

[6] H. T. Yu, Y. Yuan, and G. X. Yu, "Evaluation of influence of vibrations generated by blasting construction on an existing tunnel in soft soils," Tunnelling and Underground Space Technology Incorporating Trenchless Technology Research, vol. 43, 2014.

[7] L. M. Duan, W. S. Lin, and J. X. Lai, "Vibration characteristic of high-voltage tower influenced by adjacent tunnel blasting construction," Shock and Vibration, vol. 2019, Article ID 8520564, 16 pages, 2019.

[8] L. Jia, Y. P. Xie, and S. K. Li, "Numerical simulation for impact of blasting vibration on nearby tunnel lining safety," Vibration and Shock, vol. 34, no. 11, pp. 173-177, 2015.

[9] Y. J. Sun, Y. K. Zhao, and S. P. Zhang, "Influence of excavation blasting of new liulin river tunnel on existing tunnel," Blasting, vol. 32, no. 1, pp. 75-80, 2015.

[10] X. Xia, H. B. Li, and J. C. Li, "A case study on rock damage prediction and control method for underground tunnels subjected to adjacent excavation blasting," Tunnelling and Underground Space Technology Incorporating Trenchless Technology Research, vol. 35, 2013.

[11] D. W. Liu, G. C. Song, and F. J. Chu, "Numerical analysis of the effects of the tunnel blasting on the nearby tunneling areas," Journal of Safety and Environment, vol. 14, no. 2, pp. 64-68, 2014.

[12] M. Cardu and J. Seccatore, "Quantifying the difficulty of tunnelling by drilling and blasting," Tunnelling and Underground Space Technology Incorporating Trenchless Technology Research, vol. 60, 2016.

[13] Y. Zhou, S. L. Wang, and J. Wang, "Vibration response of an existing tunnel to adjacent blasting construction," Chemical Engineering Transactions (CET Journal), vol. 55, 2016.

[14] Y. Qian and L. Qin, "Technical research on the influence of blasting construction on the safety of existing tunnels in double track tunnels," Engineering quality, vol. 37, no. 7, pp. 56-61, 2019.

[15] D. H. Shao, H. L. Fei, C. Y. Yang, S. Q. Xiao, and G. J. Qu, "Numerical simulation analysis of influence of new tunnel blasting on existing tunnel," Engineering Blasting, vol. 23, no. 5, pp. 67-70+80, 2017.

[16] B. F. Duan, W. Z. Gong, and G. S. Ta, "Influence of small, clear distance cross-tunnel blasting excavation on existing tunnel below," Advances in Civil Engineering, vol. 2019, Article ID 4970269, 16 pages, 2019. 
[17] J. X. Zhou, Y. Luo, and X. P. Li, "Numerical evaluation on dynamic response of existing underlying tunnel induced by blasting excavation of a subway tunnel," Shock and Vibration, vol. 2017, Article ID 8628671, 10 pages, 2017.

[18] V. K. Dang, D. Dias, and N. A. Do, "Impact of blasting at tunnel face on an existing adjacent tunnel," International Journal of Geomate, vol. 15, no. 47, pp. 22-31, 2018.

[19] M. X. Zheng, M. F. Shu, Y. M. Xia, G. P. Hu, and J. H. Liu, "Influence of blasting vibration existing tunnel lining on 0 n dynamic response of high velocity railway," Railway Buildings, no. 1, pp. 94-97, 2017.

[20] Y. Z. Shi, J. F. Chai, and J. C. Ruan, “The influence of zonal multiple blasting of a large-span tunnel on its surrounding rock and antecedent tunnel," Journal of Sun Yat-Ssen University (SociNatural Science Edition), vol. 57, no. 5, pp. 72-80, 2018.

[21] T. L. Liu, T. H. Ling, Z. H. Chen, and X. Wang, "Numerical analysis of the effect of blasting vibration on existing tunnels," Traffic science and engineering, vol. 35, no. 3, pp. 79-84, 2019.

[22] Q. X. Wu, H. L. Wang, H. X. Hu, and F. Q. Zhang, "Study on blasting vibration of new undersea tunnel affecting existing tunnels," Journal of Shandong University of Science and Technology (Natural Science Edition), vol. 38, no. 4, pp. 41-49, 2019.

[23] W. P. Guo, "Influence of blasting vibration on adjacent existing tunnels," Construction technology, vol. 49, no. 21, pp. 81-84, 2020.

[24] L. L. Zhou, J. Xu, and H. Yan, "Analysis on the influence of blasting vibration on the safety of existing tunnels," Geotechnical Foundation, vol. 33, no. 05, pp. 550-554, 2019.

[25] J. X. Yu, H. C. Liu, and J. Q. Guo, "Determination of the vibration response regularity of the blasting excavation in the double-track highway tunnels," Journal of Safety and Environment, vol. 19, no. 05, pp. 1568-1575, 2019.

[26] F. Xue, C. C. Xia, and G. L. Li, "Safety threshold determination for blasting vibration of the lining in existing tunnels under adjacent tunnel blasting," Advances in Civil Engineering, vol. 2019, Article ID 8303420, 10 pages, 2019.

[27] H. L. Wu, J. Q. Liang, and X. Y. Liang, "Analysis of influence of blasting construction on existing sandstone tunnel based on FLAC3D software," Construction, vol. 42, no. 09, pp. 1794-1796, 2020.

[28] N. E. Rebello, R. Shivashankar, and V. R. Sastry, "Response of strata and buildings to blast induced vibrations in the presence and absence of a tunnel," Geotechnical \& and Geological Engineering, vol. 34, no. 04, 2016.

[29] L. Wu, F. Li, W. B. Lu, M. Chen, and F. Xu, "Vibration velocity threshold of a tunnel adjacent to surrounding layered rocks under blasting load," Explosion and Impact, vol. 37, no. 02, pp. 208-214, 2017.

[30] S. H. Hu, T. Liu, C. J. Yu, and C. Chen, "Study on prediction and control method of peak particle vibration velocit on nearby existing tunnel," Coal Technology, vol. 37, no. 03, pp. 19-21, 2018.

[31] D. M. Guo, K. Liu, W. Zhang, J. Yang, L. F. Fan, and L. Xue, "Research on failure rule and dynamic response of tunnel under adjacent blasting loads of different spacing," Journal of Beijing University of Technology, vol. 38, no. 10, pp. 1000-1005, 2018.

[32] A. K. Qian, Z. M. Chen, X. Zhu, and Y. Wen, "Optimization of blasting scheme for adjacent existing tunnels with the short reserved maintenance times," Engineering Blasting, vol. 26, no. 01, pp. 36-42, 2020.
[33] X. H. Wang, P. Du, and C. Han, "Vibration response of ground and adjacent tunnel under bench blasting for tunnel excavation," Blasting Equipment, vol. 49, no. 05, pp. 54-58, 2020.

[34] J. X. Yu, W. Z. Chen, and J. P. Yang, "Study of blasting vibration control technology of up and down cross tunnel," Geotechnical Mechanics, vol. 35, no. S2, pp. 445-452, 2014. 